\title{
An Unusual Case of a Forgotten Intrauterine Contraceptive Device for 25 Years Presented with Ectopic Pregnancy at AMDA Hospital, Damak, Nepal
}

\author{
Budhathoki B, ${ }^{1}$ Sharma $P^{2}$ Dhakal $N^{3}$ Sah $R^{4}$
}

\section{Affiliation}

1. Consultant Gynaecologist, Department of Obstetric and Gynaecology, AMDA Hospital, Damak, Jhapa, Nepal

2. Department of Family Medicine, AMDA Hospital, Damak, Jhapa, Nepal

3. Department of Anaesthesiology and Critical Care AMDA Hospital, Damak, Jhapa, Nepal

4. Department of Obstetric and Gynaecology, AMDA Hospital, Damak, Jhapa, Nepal

\section{ARTICLE INFO}

\section{Article History}

Received : $14 \mathrm{Dec}, 2016$

Accepted : 14 Jan, 2017

Published : 30 April, 2017

(c) Authors retain copyright and grant the journal right of first publication with the work simultaneously licensed under Creative Commons Attribution License CC - BY 4.0 that allows others to share the work with an acknowledgment of the work's authorship and initial publication in this journal.

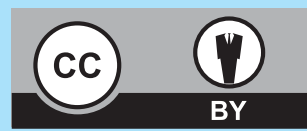

CR 6

* Corresponding Author

Dr. Bimla Budhathoki

Consultant Gynaecologist

Department of Obstetric and Gynaecology AMDA Hospital Damak, Jhapa, Nepal

Email: aarnavbimla@gmail.com

\section{ABSTRACT}

Intrauterine contraceptive device (IUCD), Copper T-380A, is widely used by more than one million women around the world. It is a long acting, reversible device with higher safety, low cost and low failure rate profile. Hereby, we reported a case of ectopic pregnancy with a forgotten IUCD. She was a 42 year woman who had forgotten the IUCD placed in her uterus 25 years back. She was totally unaware of the follow up visits, its removal and that IUCD was causing a problem to conceive for the second time. The inserted IUCD was incidentally discovered on ultrasonography, when she presented with history of lower abdominal pain and vaginal bleeding. On investigation, she had right tubal pregnancy with moderate fluid in pelvic cavity. So, emergency laparotomy was perfomed followed by right salphingectomy and removal of IUCD.

\section{KEYWORDS}

Contraception, ectopic pregnancy, intrauterine contraceptive device

\section{Citation}

Budhathoki B, Sharma P, Dhakal N, Sah R. An Unusual Case of a Forgotten Intrauterine Contraceptive Device for 25 Years Presented with Ectopic Pregnancy at AMDA Hospital, Damak, Nepal. BJHS 2017;2 (1)2 : 142-144. 


\section{INTRODUCTION}

The Intrauterine Contraceptive Device (IUCD), is one of the most commonly used method of contraception with over one million women accepting it worldwide. ${ }^{1}$ IUCD is highly effective, reliable and long acting reversible contractive device. ${ }^{2}$ The acceptability is high with this device. It is easy to insert and remove whenever patients prefer. It can be inserted in post menstrual, post abortal, post delivery or post puerperal period. Copper-T exhibits its contraceptive effects through the dissolution of copper ions, which creates a spermicidal, sterile inflammatory response at the level of the endometrium and copper-rich cervical mucus that decreases sperm motility. ${ }^{3}$ Its principal mechanism of action is to prevent fertilization by affecting sperm motility. ${ }^{2}$ However rarely its unwanted effects are bleeding disorder, cramping pain, discharge per vaginum, pelvic inflammatory disease, perforation of uterus on insertion, displacement of device in situ and in abdominal cavity and ectopic pregnancy.

The average annual failure rate of CU-T 380A IUCD is 0.4 percent or less and after 12 years of use, the cumulative failure rate is 2.2 percent, which is comparable to that of female sterilization. ${ }^{4}$

Ectopic pregnancy is a major cause of maternal morbidity and occasionally mortality. In recent decades, the incidence of ectopic pregnancy has increased; contraceptive failure has been considered one of the factors. ${ }^{5}$ Ectopic pregnancy is simply a fertilized ovum implanted outside the uterine cavity, most common involvement being fallopian tube. Risk factor for ectopic pregnancy are PID, endometriosis, IUCD use, tubal surgery, pregnancy after tubal ligation, progesterone only pills use, ovulation induction and assisted reproductive techniques. ${ }^{2}$ The incidence of pregnancy is less but the risk of ectopic is more if pregnant occur in IUCD users, risk being approximately 1 in 20 . A WHO multicentric study found that IUCD users are $50 \%$ less likely to experience an ectopic pregnancy than non-contraceptive users. ${ }^{4}$

\section{CASE REPORT}

A lady of 42 years, P1L1 with last childbirth vaginally 25 years back presented at AMDA Emergency Department in morning with complains of minimal bleeding per vaginum since 6 days associated with lower abdomen pain for last 2 days. The pain was moderate type radiating to epigastric region. Her last menstrual period was 18 days back but the flow was scanty. Her pattern of menstrual flow had reduced to minimal and used to have dysmenorrhea since her last childbirth. Afterwards she had planned for conception but she had not consulted doctors for infertility.

On examination she was obese, pale but hemodynamically stable with mild elevated in blood pressure. Her abdomen was tender on palpation, mostly on the right side. On per speculum, minimal altered bleeding was seen, cervix looked normal. On bimanual examination, there was tenderness on right fornix, cervical motion tenderness was present and size of uterus was difficult to delineate. Her pregnancy test was twice repeated and came out to be positive but she was not expecting to be pregnant, as she had difficulty in conception for such a long time since her last childbirth. Then she was advised to do an ultrasound of abdomen and pelvis. Her ultrasound report showed small fibroid in fundus with IUCD in uterine cavity, gestational sac of $10.4 \mathrm{~mm}$ in right adnexa with moderate fluid in pelvic cavity. History regarding IUCD revealed that she had forgotten it after which was inserted after five months of her last childbirth on her first resumption of menstruation at a near by health post. She had no proper knowledge of its duration of use and when to remove. She assumed that the contraceptive effect of it would wear off on its own after certain period of time and ignored its presence, as she had no serious effect.

Afterwards she was admitted in the hospital and planned for laparotomy. Her blood report showed hemoglobin of 8.0 $\mathrm{gm} / \mathrm{dl}$. Her pulse rate and abdominal pain was increasing, however her blood pressure was high.

Before starting laparotomy, IUCD with missing thread was removed with forceps. Laparotomy was proceeded, and the findings were - hemoperitoneum of 1.5litres, right tube edematous, bulge at ampula, oozing from the fimbrial end. Right total salphingectomy with periteonal lavage was done. Patient was stable throughout and in postoperative period. Patient did well and was discharged on third post-operative day.

Figure 1. IUCD with no string

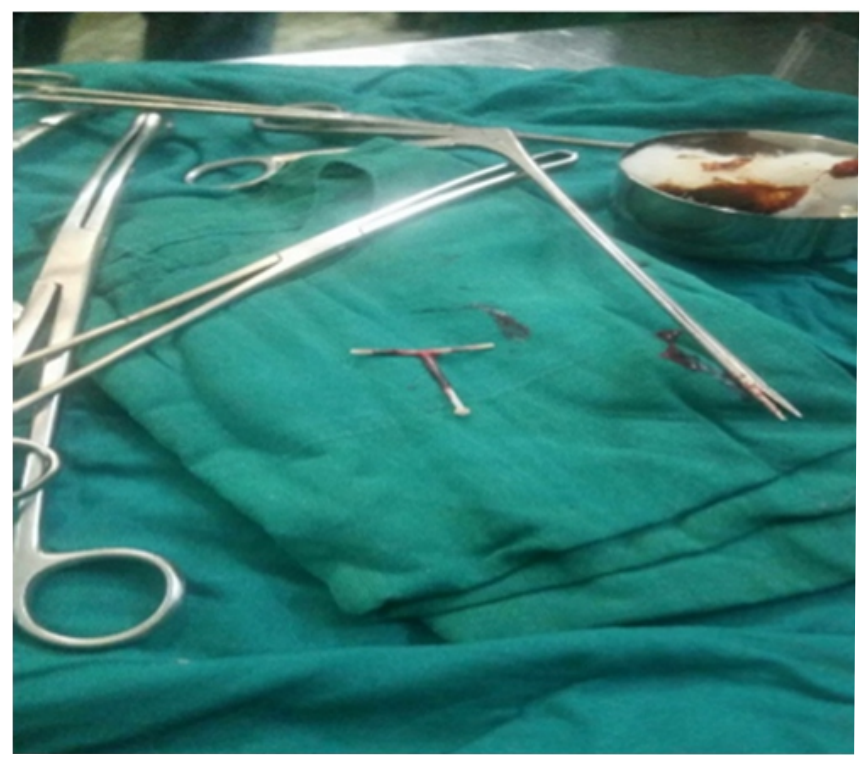




\section{Figure 2. Right tube with ampullary bulge}

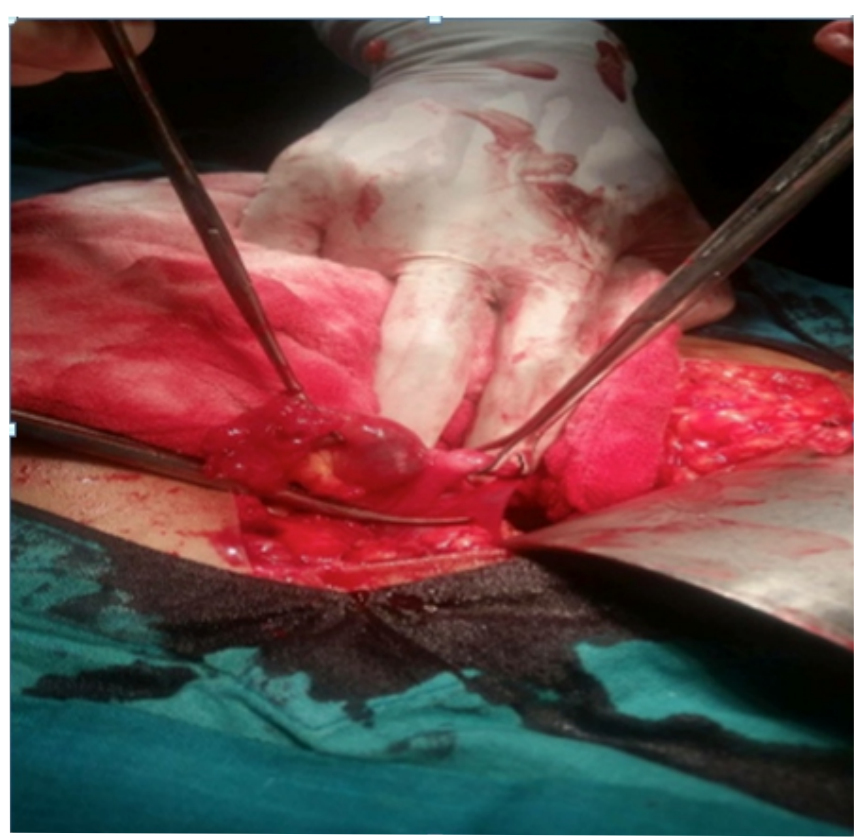

Figure 3. Right tube after surgery

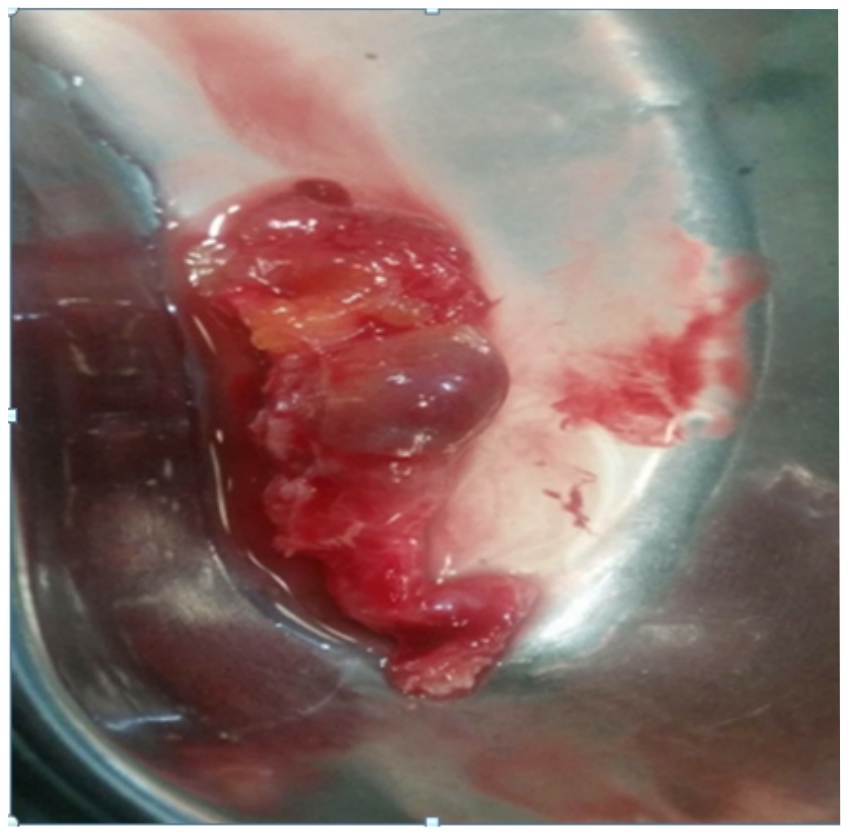

\section{DISCUSSION}

Studies have shown that device may be less effective for ectopic pregnancy prevention then for intrauterine pregnancy prevention. ${ }^{5}$ The risk of ectopic pregnancy resulting from contraceptive failure varies according to the contraceptive method used. Condoms use show no increased risk, oral contraceptive pills show a slightly increased risk, but in contrast IUCD use and tubal sterilization, both show strongly increased risk. ${ }^{6}$ In IUCD users, risk of pregnancy is less but if pregnant, chance of being ectopic is more. This patient was not pregnant for 25 years but as she conceived it turned out to be ectopic. There are studies, which showed that extended use of IUCD would prevent pregnancy. So it is not copper only but the device itself plays role for prevention of pregnancy. As in this case, the copper was getting shed. So, regarding the lifespan of copper IUCD, the fact is that inert IUCDS (i.e. unmedicated IUCD such as lippes loop) has demonstrated contraceptive efficacy via the local inflammatory effect on endometrium, raising the theoretical possibility that medicated IUCD may exert some of contraceptive effect, even after copper concentration is undetectable. $^{3}$

Hence, proper counseling of the contraceptive method being used should be done. One should focus on the need for follow up and examination periodically and if any signs and symptom occurs. Long-term users are at risk of pelvic inflammatory disease, perforation of uterus on heading to menopause and perimenopausal bleeding.

\section{CONCLUSION}

Family planning programs should aim to improve quality of services through proper counseling and follow-up services, which helps to support women's continuation of effective methods. This case report showed that the quality and level of counseling to the patient was very poor. It may also be the possibility the patient was told but she may have forgotten, though she denied this fact. Though, IUCD in place for such a long time did not cause serious effect, it should not be left in situ for more than its duration as complications can occur at any stage, mild or serious. So proper counseling of device and follow up mandatory even if no side effect of the device, should be stressed upon.

\section{REFERENCES}

1. Desai AY, Dnyaneshwar S, Pai VD. Forgotten Intrauterine Contraceptive Device- An Unuasal Cause of Enterouterine Fistula. Journal of Surgery. 2015:1(1). 1-6.

2. Cunningham FG, Leveno KJ, Bloom SL, Hauth JC, Rouse DJ, Spong CY. Willams Obstetrics. 23 $3^{\text {rd }}$ edition. New York: Mc Graw-Hill. 2010. 238-239.

3. Wu JP, Pickle S. Extended use of the intrauterine device : a literature review and recommendations for clinical practice. Contraception. 2014;89:495-503.

4. Cathy S. Intrauterine Devices. $2^{\text {nd }}$ edition. Watertown MA: Pathfinder International; 2008.

5. Li C, Zhao W-H, Meng C-X, Ping H, Qin G-J, et al. Contraceptive Use and the Risk of Ectopic Pregnancy : A Multi-Center Case-Control Study. PLOS ONE 2014;9(12),p.e115031.

6. Mol BMJ, Ankum WM, Bossuyt PMM, Van Der Veen F. Contraception and Risk of Ectopic Pregnancy; A Meta -Analysis. Contraception. 1995; 52:337-341. 